Portland State University

PDXScholar

\title{
A standardization of the "Children's Speechreading Test" on normal children
}

Lorna Helen Newcombe

Portland State University

Follow this and additional works at: https://pdxscholar.library.pdx.edu/open_access_etds Let us know how access to this document benefits you.

\section{Recommended Citation}

Newcombe, Lorna Helen, "A standardization of the "Children's Speechreading Test" on normal children" (1969). Dissertations and Theses. Paper 1285.

https://doi.org/10.15760/etd.1284

This Thesis is brought to you for free and open access. It has been accepted for inclusion in Dissertations and Theses by an authorized administrator of PDXScholar. Please contact us if we can make this document more accessible: pdxscholar@pdx.edu. 
A STANDARDIZATION OF 'PHE "CHILDREN'S SPEECHREADING TEST" ON NORNAL CHILDREN

\author{
by \\ TORNA HELEN NESCOMBE
}

A paper submitted in partial fulfillment of the requirements for the degree of

WASTER OF SCININE IN TEACHING with an emphasis in

SPEECH FATFOLOGY AND AUDIOLOGY

\author{
Portland State University \\ 1969
}




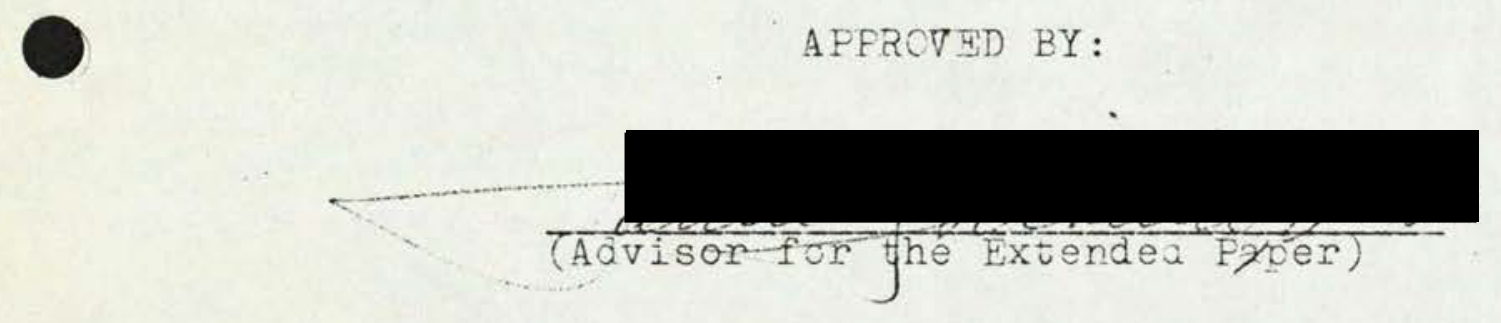




\section{ACKNONLEDGMENTS}

This paper was first written for Dr. James Maurer in Sp. 501 - Research: Lip Reading, during the Spring Term, 1969. 


\section{TABLE OF CONTENTS}

PAGE

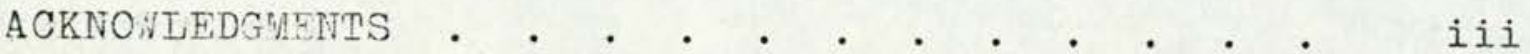

CHAFTER

I INTRODUCTION . . . . . . . • . .

The Furoose of the Study . . . . . 1

A Historical Survey of Lip-Reajing . ?

II MFTEODS AND TECHNIQUES . . . . . . . 6

Procedures : . . . . . . . 6

Results . . . . . . . .

Discussion . . . . . . . . . 8

III SUMMARY AND CONCLUSIONS . . . . . . . 9

BIBLIOGRAPHY • . . . . . . . . . . . . 10

APPENDIX

A Children's Speechreading Test . . . . . 11

B C:lculations - Data 12

f Percentile Scores and Range of Scones. . $\quad 14$ Divided by S.D. 
-

0

0 


\section{GHAFPER I}

\section{TNTRODUCTICN}

This study is a limited standardi ation of the "Chilren's Speechreading Test" designed by Dr. Dolores S. Butt of the University of New Mexico. After studying the development of language skills in young acoustically handicapped children, she randomly selected subjects from 10 nursery schools and primary departments of scrools for the deaf and administered her test to these children (Butt, 1968). The mean score for girls on this test was not significantly superior to the boys' score. Dr. Dutt felt that her test could be useful in the following ways:

1. Placement of deaf children beginring their education at $a$ new school or clinic.

2. Evaluation of progress in the early years of a deaf child's training.

3. Gather ng information on the early development of speechroading skills.

Iittle is known about kow speechreading ability develops in an inoividual and is a survey of lip reading will show, few tests have been developed to assess children's lip reading ability. Since relatively few children's lip reading tests have been developed, and since Dr. Butt standaraized her test on hearing handicapped children, it was felt that a pilot study on normal ch-laren in the primary grades might be useful both for comparison and future implication for a more complete standardization of the "Chilaren's Speechreading Test".

\section{The Finno:e of the Study}

The puroose of the present study is to provide a limited standardization of the "Children's Speechreading Test" on normal he ring children. Although Dr. Butt indicates 
s me relation of her test to intelligence, no attempt was made in this pilot study to correlate mental ability with speechreading ability.

The "Children's Speechreading Test" reproduced in complete form in Appendix 4 , was administered to 20 normal hearing children, all of whom were in the first grade. Information in the form of raw scores was then to utilized in calculating the standard deviation and percentile scores. Information ained from administering the test was also to be utilized to predict further investiotion regarding the usefulness of this test. In addition a further puroose of this pilot project was to conpile the materiala necessary for administration of the test for future use in the Portland state University Speech and Hearing Clinic.

\section{A Historical Survey of Lip-Reading}

In 1871, A.M. Bell originated Visible Speech Symbols. This was the first real consideration given to lipreading in Ameriç. Edward Nitchie worked with lipre dirg instruction in New York (Nitchie, 1912). His method involved three principles; chysical, mental, and spiritual. The physical was irvolved with seeins and krowing the movements, homophenes, and variations of movement. the mental aspect related to synthesis, visual and mental integration, and concentration. The spiritual involved motivational attitudes. Nitchie believed lip reading training should never begin before the age of four years (Nitchie, 1912). During the course of his life- . time Nitchie shifted from an analytical to a synthetic approach. the synthetic aporoach involved concents, whereas the anilytical approach involved speech as movement, instantaneous understandinz, and observation.

Mirtha Bruhn ounded a sahool based upon the ruellerWalle method of lipreading. Ihis was an analytic technique involving ravid rhythmic syllable drill (O'Neill, 1951). She believei that sceech was movament, and transitions from movement to movement. Lipreadirg ability, then, was augmented by 
close orservation of the movements of the lips from one sound posit on to another (C'Neill, 1961). Bruhn considered lipreading an art, which was influenced by two factors, practice and innate talent. Some of the goals for the student were:

1. Ability to feel sound sensations.

- Ahility to observe sound visually.

3. Maximum bel from alertness and quickness.

4. Stress on movements and c mp rison of movements.

5. Help from the teacher with syllables and phrases.

Sounds were classified by Drubn as easily seen, often obscure, and obscure. Here techique demanded entire concentration of the lipreader on visual cues. Drill was an important part of Bruhn's teaching method, with practice sessiuns lasting 30 minutes at a time. Bruhn also used group techniques.

Cora and Kose Kinzie opened a school krown as the Kinzie School of wpech reading (O'Neill, 1961). Cora had been a medical student who gradually lost her hearing. As a result she took the bruhn course in lipreading and then turned from medicine to the teaching of lipreading. The Kinzie technicue was a combination of thcse of Nitchie and Druhn. It included sentences such as those employed by Nitchie and Bruhn. The sisters wrote a bock called "Lip reading for the beafened Adult", and Rose Kinzie wrote a series of lessons for children. These lessons were graded: Grade 1 - vosabulary building, objects, pictures, and sctions; Grade 2 - imitation of actions; and Grade 3 - formal lesson plans using drama.

Another method started in Michigan around 1927 by Anna Dunger was the Jena method derived from Karl Brauckmann of Jena, German (O'Neill, 1951). Her technique was somewhat more scientific than the others and involved kinesthetic as well as visual cues. In this technique there were five forms of speech communication: 1) Mov ment or physical 
placement of the articulators; 2) Audible sounds associated with the movements; 3) Visibility; 4) Nuscles of facial expression; and 5) Gesture.

In 1944 Ewing found it advantageous to use the hearing aid in conjunction with speech re ding. Fe found that $/ p, f$, o,u/ were the most audible (O'Neill, 1961).

Stowall, ramuelson, and Lehman (1928) wrote a book directed to the needs of slightly deafened and hard of hearing children. High frequency sounds were studied first; and these were found to be more difficult and particularly important in sensori-neural losses. A low voice was used with no gestures and repetition was stressed. Informal lessons with increasingly longer tire periods for the older grades were utilized. These lessons involved; commands, lother Goose rhymes, ridales, colloquisl questions and stories. In 1938 Doris Varkovin prouuced the Varkovin films, which were training flms from life situations (C'Neill, 1951). His was the synthetic system. It involved distinguishing verbal and nonverbal clues. $4 V K R T$ or audio-Visual-Kinesthetic-khythmic-Tactile perceptions were to be utilized. In conjunction with Marie Moore, Markovin constructea a manual for the teacher of speech reading (Markovin, 1948). Markovin dia not feel that drill on syllables, unrelated to life situations, should be used (O'Neill, 1961).

Varie Mason of Ohio jtate University also made 30 films which utilized the anal tic approach. In these films the speech reader was supposed to watch the mouth, write down words, and gain the key thoughts. In the chilaren's films, $\mathrm{visual}$ hearing involved the phonetic aproach, or the perception and recognition of visual and kinesthetic cues (Nas $n, 1942)$. In these films, which were basically teaching films, t e souna could be either on or off. Meson called her nethod "Visual Hearirg" (O'Neill, 1951). Whildin an scally constructe a set of materials, 
"Speech keading for the Hard of Hearing uhild," directed toward children in the intermediate grades ( $0^{\prime N e i l l, ~ 1961) . ~}$ Whiluin's materials included the use of words, sentences, stories, and questions (O'Neill,1951). It's purpose was not to present theory, but to present lipreading to the child. Oyer believed that lipreading tests were designed to measure the person's ability to understand what a speaker was saying, by concentration on his lip movements and other facial muscles. Lipreading t sts coula also be used to measure the effects of lipre ding training, and to aid in the proober placement of inuividuals within a trainirg orogram (oyer, 1951).

Utley standardized Mon's children's lipreading test on alults, and on chilaren. She found that the ability to lipread sentences was more reliably predictea from an ability to lipread senterces than stories.

\section{Summary}

speecreading has progressed from the originati $n$ of visible sreech symbols to the teaching of speechreadirg. In adaition, tests for assessing speechreading ability, both in children or adults have been developed. A review or at least historical overview cf lipreading showed that few children's lipreading tests had been developea. for this reasor further nvestigation of Dr. Butt's "Children's Iipkeading Test", in this case, in the form of a limited stardardization, might be of value. 


\section{CHAPTER II}

\section{METEODS AND TECHNIQUES}

\section{Procedures}

In this study 20 normal hearing children or children who had tested normally during the school hearing screening program, were administered the "Children's upeechreading Test" developed by Dr. Dolores s. Dutt of the Uni ersity of New Mexico. The full test has been reproduced in Appendix A. The test is intended for clinical examination of any hearing handicapped child. The easiest items can be performed by a one year old child (sutt, 1968). Dr. Butt found that the more difficult items were usually understood b. a 3 year old child. These were items such as: "Give me the big ball". Although Dr. Eutt tested children up to nine years of age in her standardization on hard of hear $\lrcorner$ g children, she felt that the $t$ st should not require reading or writing ability, or oral answers. The vocabulary of the test consists mostly of nouns and verb with words being chosen fom the first one thousand words of standard vocabulary lists (Butt, 1968). All the phonemes of speech were included. Both single word nd complete sentences are utilized in the questions. Dr. Butt felt that individual testing yielded more information to the exaniner.

The criteria for selection of children for the sample utilized in the pilot study were that the children be in the first graâe and of normal intelligence as evidenced by their - presence in the first grade, not be any formal testing. The children were between the ages of 5 years 5 months and 8 years 7 months. The school personnel, in this c se their teacher, were instructed to randomly select the students to be tested. These students ware enrolled in classes at Hayhurst and Bridlemile schools in Portland, Oregon. None of the chilaren had 
any special physical, mental, or social problems.

Binaural masking was utilized to mask out the voice of the clin cian administering the test. The subject was sested four feet from the clinician in good lighting. No other peovle were in the classroom in which the test was administered so the room was quiet. The test was administered individually, with the clinician using a quiet voice, but utilizing conversational speech. The items were presented at a conversational rate with no special emphasis on particular words.

\section{Results}

Out of a possible total of 70 items that could be performed correctly by the subjects, scores varied 34 to 59 correct. The scores for the entire sample have been listed in Appendix B.

Results aporoach a normal probability curve in this study. the scores appear to cluster around the center, or the test results showed the scores appeared to cluster closely arouna the mean. The range of scores was from 59 to 34 and the standard deviation was 6.75 . Two measures of variabil ty are included in Appendix $C$, the percentile scores, and the range of scores dividea by the standard deviation.

A t test was run comparing the mean of Dr. Butt's hard of hearing seven year olds to the mean of this study. Her $?$ year old group seemed to be most corparable to the group tested in this study with regard to age. The $t$ obtained of 2.17 indicated that the mean score of the nomal hearins group tested in this study was significantly sreater than the mean of the seven year old group of card of $h$ aring children tested b Dr. Butt at the .05 level of significance. Jalculations can be seen in Appendix B. Since the variability of Dr. Dutt's group was not commable, a t test when variances differ was 
comouted. These calculations can be seen in Appendix $B$.

\section{Discussion}

A hypotretical reason that the mean of this study may have been hicher might be that the socio - economic bockground of the child was higher than that of the population used in Dr. Dutt's study. In addition the normal hearing children are exposed to commicaticn and are exposed to the basic words utilizea in Dr. Butt's test with more frequency than the dasf. 
GHAPTER III

SU VIRY AND CONCLUSIONS

In summary we have sought to provide a limited standardization of the "Children's Speechreading Test" on normal hearing children. Percentile scores, standard deviation, and $t$ sccres were computed. The mean score of the normal hearing grcup in this study is significantly higher than the mean score of the 7 year old group of hard of hearing children at the .05 level.

Further studies might involve increasing the population s nce there was a depressed dynamic range. It might be interesting to construct a test that would orovide a more discriminative task for good or poor lipreaders, or both. Item analysis and test-retest might be usful. 


\section{BIBLIOGRAPHY}

1. Bruhn, Narth, The Nueller-Walle Nethod of Iip reading for the Deaf, I,ynn, Nass: The Nichols Press, 1929.

2. Butt, D.S., "A Speechreading Iest for Young Children", The Volta Review, April, 1968.

3. Kinzie, Cors and "ose, Lip Reading for the Deafened 4dult, Chicago: The Jokn Winston Co. 1951.

4. Morkovin, B.V. and Moore, L.M:, A Contextual Systematic Aoproach for Speech Radirg, Los Angeles: University of southern Colifornia, $1948-49$.

5. Nitchie, Edward, Lipreading, Principles and Practice, New York; $\bar{H} \cdot \overline{\text {. Stokes Co., } 1912}$

6. O'Neill, John, Jisual Communication, Englewood Cliffs, N.J. Frentice Hall, Inc., 1951

7. Oyer, H.J., Auditor Communication for the Hara of Hearing, Englewood Cliffis, N.J., Prentice Hall, Inc., 1956

8. Nhildin, O.A., The New Vethod in upeech keqding For The Hid of Hearin ghild, Nestminster: John " Jckenrode, 
APPENDIX A

\section{CHILDREN'S SPEECHREADING TEST}

Dolores S. Butt, Ph.D.

Assistant Professor of Speech

University of New Mexico

Albuquerque - New Mexico

Name

School

Examiner

Years of Training

Hearing: Right Left $\therefore$

Age and Cause of Hearing Loss
Speechreading Test Score

Test Date

Birthdate

Age__ Sex

Mental Age IQ

\section{TEST A: Informal Checklist for Children Under Three Years of Age}

Normal Age of

Appearance

2 months

10 months

12 months

18 months

21 months

24 months

24 months

(ro norms)
1. Does child attend to face?

2. Does child respond to gesture?

(Pat-a-cake, Bye-bye, etc.)

3. Does child inhibit on command?

(No-no with gesture)

4. Does child understand simple questions? (Where's Daddy?)

5. Will child follow simple commands? (Give it to me; Come; Look; etc.)

6. Can he speechread his own name?

Tiie names of others?

ob; $\epsilon$ ts? (milk, shoe, etc.)

Or concepts? (up, hot, good boy, etc.)

7. Can he repeat the words he speechreads? (Hello, Mama, etc.)

8. Can he answer questions?

(What is your name? How are you?) 
PART I. IDENTIFICATION OF OBJECTS. Place objects in random order on the table. Encourage child to watch your face while you name the object three times, then allow child to indicate the correct object. Replace object after each task. It is helpful to keep each set of objects in a separate box.

Present: fish, shoe, ba11, train

1. Show me the fish.

2. Show me the ball.

3. Show me the shoe.

Present: top, airplane, baby, gun.

4. Show me the airplane.

5. Show me the top.

6. Show me the gun.

Present: chair, toothbrush, button, table

7. Show me the chair.

8. Show me the button.

9. Show me the toothbrush.

Present: fork, table, car, bus

10. Show me the table.

11. Show me the car.

12. Show me the bus.

Present: candy, watch, bel1, hat

13. Show me the bell.

14. Show me the candy.

15. Show me the watch.

PART II. NUMBERS. Place five blocks on the table. Demonstrate the first task by saying "four" and scooping four blocks toward you. Replace the blocks, repeat the word "four" and indicate for the child to push the correct number toward you.

16. one

17. three

18. two

PART III. PICTURE IDENTIFICATION. Present Test $\underline{\text { Card }}(\underline{a})$ and say:

19. See baby? Where is baby?

20. Where is the flower?

Present: Test Card (b)

21. Where is mother?

22. Where is father?

(or daddy)

23. Where's the boy?

Present: Test Card (c)

24. Point to the bird.

25. Point to the dog.

26. Point to the

hammer.

Present: Test Card (d)

27. Point to the T.V. (or television)

28. Point to the boat.
29. Point to the home. (or house) 
Directions: Sit about four feet from the child in a well lighted room. Attract the child's attention to your face before presenting each item. Speak to the child naturally but in an inaudible voice. Present the spoken material from the front view the first time, then repeat once or twice with your face slightly turned so the child sees a $3 / 4$ view. If the child tires, allow him to rest.

Each correct answer receives one point. Correct answers are credited even if the child seems to be guessing.

Test Materials: The examiner can obtain these materials from a toy store.

1. Toys, durable and realistically colored, and in correct proportion: 3" baby doll bell 1" baby doll cellophane wrapped candy doll bed, table and chair toy cup, fork, and spoon doll shoe car airplane

bus

train

gun

top toy wristwatch child's toothbrush 1 " rubber bal1 $1 / 2$ " rubber ball cow chicken pig horse button fish

2. Blocks: five $1^{\prime \prime}$ counting blocks of uniform color.

3. Color chips: 1" colored paper squares: yellow, blue, black, white, red, and brown.

4. Ten picture cards $8-1 / 2^{\prime \prime} \times 11^{\prime \prime}$ that can be constructed from colored pictures in children's books or magazines. Each picture must be realistic and easily recognized by a child:

(a) baby, kitten, flower

(b) mother, father, boy, girl

(c) bird, dog, hammer, spoon

(d) television set, motor boat, house, bed

(e) girl putting on her shoes; boy eating at the table; girl or boy swimming.

(f) child playing with a ball; child taking a bath; girl jumping rope.

(g) child in bed; child reading a book; child playing with blocks.

(h) ipple, water faucet and glass of water, pie, butter

(i) an orange; milk carton and glass of milk; loaf of bread and a piece of bread; a vegetable.

(j) banana, cookies, cooked meat, soup.

5. Paper dolls with clothes, Boy and girl dolls should be mounted on separate $8-1 / 2 \times 11^{\prime \prime}$ cards, and the clothing should be cut so that it can easily be placed in position: Two dolls with pants, shirt, dress, pajamas, hat, coat, and shoes. 
PART IV. COLOR IDENTIFICATION. Place color squares on table, three at a time. Say the name of one color and reach your hand out to receive it. Change color cards for each item.

Present: biue, yellow, and white. 30. blue

Present: 미ack, white, and brown. 31. white

Present: ye 1ow, red, and brown. 32. brown

PART V. ACTIONS.

Present $\underline{\text { Test }}$ Card (é)

33. Who puts on her shoes?

34. Who eats her supper? (or dinner)

$\underline{\text { Present }} \underline{\text { Test }}$ Card (f)

35. Which one plays ball?

36. Which one takes a bath?

$\underline{\text { Present }} \underline{\text { Test }}$ Card $(\mathrm{g})$

37. Who goes to bed? Who sleeps in bed?

38. Who reads a book?

PART VI. FOODS.

Present Test $\underline{\text { Card }}$ (b) to child. Allow him zo examine it and proceed.

39. Show me the apple. 40. Where is the water?

41. Point to the pie.

Continue with Card (i)

42. Show me the orange. 43. Where is the milk? 44. Where is the bread?

Continue with Card (i)

45. Show me the banana. 46. Where are the cookies? 47. Show me the meat.

PART VII, DESCRIPTIVE WORDS. Place on the table a large ball and a sma11 ball, a 3" baby doll and a 1" baby doll.

48. Give me the big ball. Give me the little ball.

49. Give me the big baby. Give me the little baby,

(The child must respond with correct object and size each time.) 
PART VIII. PARTS OF THE BODY. Put your hand on your face and say, "This is my face. Where is your face? Show me your face." Repeat this demonstration until the child understands what is expected.

50. Where is your mouth?

53. Show me your teeth.
51. Where are your eyes?

54. Show me your arm.
52. Where is your nose?

55. Where are your feet?

PART IX. ANIMAL NAMES. Place the animals on the table in random order. Include: chicken, pig, sheep, cow, horse. Replace after each item.

56. Give me the cow. 57. Give me the horse. 58. Give me the pig.

59. Give me the chicken.

PART $X$. CLOTHING. Place on the table a paper doll mounted on 8-1/2 x 11 " cart. Use a boy or a girl do1l according to the sex of the child. Place the doll's clothes beside test card. Demonstrate the first item. "Put on his (her) pajamas." Replace each item before proceeding with the next item.

60. Put on his (her) shoes.

62. Put on his shirt (her dress).
61. Put on his (her) coat.

63. Put on his (her) hat.

PART XI. SIMPLE DIRECTIONS。 Place these objects on the table: chair, bed, baby, cup, table.

64. Put the baby to bed. Put her in bed. Go to bed, baby.

65. Put the spoon in the cup. Put it in the cup.

66. Put the fork on the table. Put it on the table.

PART XII. ACTIVITIES. Stand up and gesture for the child to stand. Say, "Stand up. Do what I do. Can you hop?" Hop and encourage the child to perform this action as a demonstration. Avoid gesturing with the actual test items to follow.

67. Can you jump? Jump.

68. Can you walk? Walk, Walk to the door.

69. Open the door. Go open the door. Open it.

70. Come here, Come. 


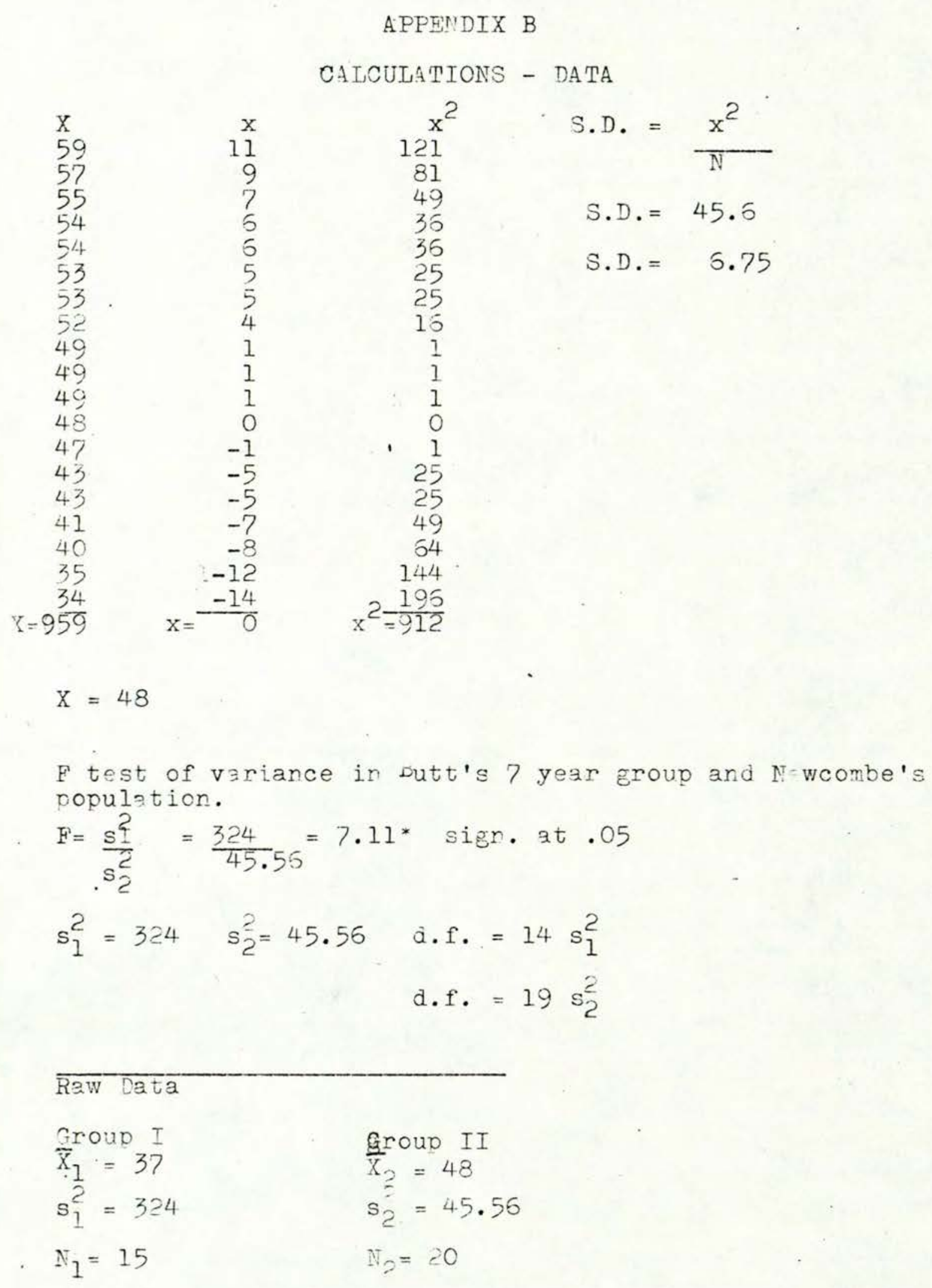


I test when variances differ

$$
\begin{aligned}
& \mathrm{S}_{\overline{\mathrm{x}}_{1}^{2}}^{2}=\frac{324}{14}=23.14 \quad \mathrm{~S}_{\overline{\mathrm{x}}_{2}}^{2}=\frac{45.56}{19}=2.39 \\
& t_{1}=2.145 \quad t_{2}=2.093 \\
& t=(23.14)(2.145)+(2.39)(2.093) \\
& (23.14+2.39) \\
& t=2.14 \\
& t \text { test for samples } \\
& t=\bar{x}_{2}-\bar{x}_{1} \\
& \sqrt{s_{x^{2}}+s_{x_{1}}} \cdot \sqrt{23.14+2.39} \\
& =\frac{11}{\sqrt{25.53}} \\
& =11=2.17 \\
& \sqrt{5.05}
\end{aligned}
$$

the mean scores of the normal hearing group in this study is significantly higher than the mean score of the 7 year old group of hard of hetrirg children tested by Butt at the .05 level.

Formulas obtained in Basic S+atistical Metrods (2nd Fdition) Downie, N.M., Heath, R.w., New York: Harper, kow, 1965 


\section{APPENDIX $\quad$ S}

PERCENTILE SGORES AND RANGE OF SCORES IVIDED BY S.D.

Percentile Scores

H. ghest score $=59$

Lowest score $=34$

Range $=25$

$\begin{array}{llcc}\text { Scores } & \text { Frequency } & \text { Cumulative Frequency } & \text { Cum.\% } \\ 55-59 & 3 & 20 & 100 \\ 50-54 & 5 & 17 & 85 \\ 45-49 & 5 & 12 & 50 \\ 40-4 & 5 & 7 & 45 \\ 35-39 & 1 & 2 & 10 \\ 30-34 & 1 & 1 & 5 \\ & -\frac{1}{20} & & \end{array}$

Fercentile Equivalents

\begin{tabular}{lll}
\hline$X-X$ & $\%$ ile & Raw Score \\
\hline 12 & 5 & 34 \\
13 & 10 & 35 \\
18 & 15 & 40 \\
19 & 20 & 41 \\
23 & 25 & 43 \\
24 & 35 & 44 \\
-5 & 40 & 47 \\
26 & 45 & 48 \\
27 & 50 & 49 \\
30 & 55 & 52 \\
31 & 70 & 53 \\
32 & 80 & 54 \\
33 & 90 & 55 \\
35 & 95 & 57 \\
37 & 100 & 59
\end{tabular}

Range of scores for Normal Fopulation

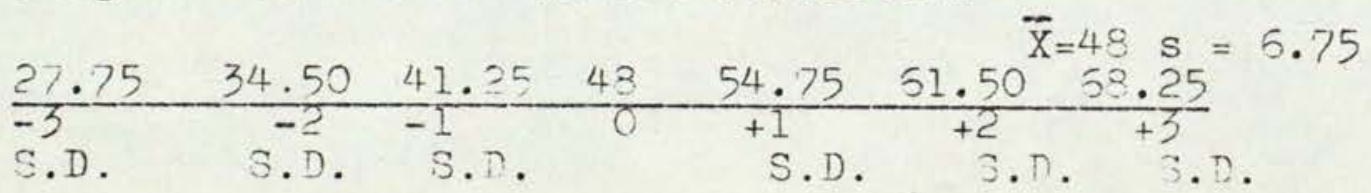

